\title{
Sumberdaya Teripang (Holothuroidea) Di Kepulauan Sekotong, Nusa Tenggara Barat
}

\author{
Sea Cucumber (Holothuroidea) Resources at Sekotong Islands, West Nusa Tenggara
}

Eddy Yusron

Pusat Penelitian Oseanografi, Lembaga Ilmu Pengetahuan Indonesia

Jalan Pasir Putih No. 1, Ancol Timur - Jakarta Utara 11048

\begin{abstract}
Observation on sea cucumber diversity was carried out at coastal waters of Sudak and Nanggu Islands in the West Part of Sekotong Island, April and June 2002. Sampling was done by using a transect quadrant of $1 \mathrm{~m} \times 1 \mathrm{~m}$. This sampling and observation on its microhabitat were conducted by scuba diving. Analyses on the sea cucumber community structure were based on its frequency of occurance, diversity, and density. The results showed that at both locations 11 species of sea cucumber were found where Holothuria scabra, H.atra, $\mathrm{H}$ nobilis, and Bohadschia marmorata were predominant, common and more evenly distributed than the other species.
\end{abstract}

Key Words : Diversity, Density, Occurance, Sekotong, Transect quadrant

Diterima: 16 Juni 2002, disetujui 15 Febuari 2003

\section{Pendahuluan}

Di perairan Nusa Tenggara Barat saat ini terdapat sekitar 18 jenis teripang komersial. Teripang komersial ini termasuk kelas Holothuroidea, suku Holothuriidae dan Stichopodidae. Jenis teripang yang termasuk dalam kategori utama adalah teripang pasir (Holothuria scabra), teripang perut hitam $(H$. atra), teripang susuan ( $H$. nobilis), teripang beras (Holothuria sp) dan teripang nanas (Thelenota ananas), sedangkan yang termasuk bernilai ekonomi menengah adalah teripang lotong (Actinopyga lecanopra) dan teripang bilalo (A. mauritiana). Jenis-jenis lainnya termasuk dalam kategori rendah.

Produk perikanan teripang merupakan salah satu hasil laut yang telah lama menjadi komoditas perdagangan Internasional yang biasa dikenal dengan istilah "beche-de-mer" (Sloan 1985; Eys 1986; Aziz 1987; Conand \& Sloan 1989). Kebutuhan akan produk ini cenderung meningkat dari tahun ke tahun, dengan produksi sampai saat ini tergantung dari pemungutan/penangkapan stok alami oleh para nelayan. Perairan Teluk Sekotong yang mempunyai lahan perairan yang cukup luas dan memiliki banyak pulau-pulau kecil, diduga dihuni oleh sejumlah jenis teripang yang dapat dieksploitasi untuk kebutuhan makanan rakyat maupun untuk komoditas eksport, karena mempunyai harga yang cukup baik, berkisar antara Rp 50.000,- sampai Rp 350.000,$\mathrm{kg} / \mathrm{kering}$. Eksploitasi yang sering dilakukan secara intensif tanpa melihat jenis dan ukurannya yang mengakibatkan berkurangnya stok alami di beberapa wilayah perairan tersebut. Oleh karena itu perlu usaha pelestariannya dan pembudidayaannya untuk mengurangi pengambilan stok alami yang berlebihan. Untuk mendapatkan hasil yang optimum perlu disertai penelitian dasar, khususnya yang berkaitan dengan kelimpahan, kepadatan dan frekuensi kehadirannya. 


\section{Metode Penelitian}

Penelitian dilakukan pada 2 lokasi yang meliputi Pulau Sudak dan Pulau Nanggu yang termasuk dalam kepulauan Sekotong, Lombok Barat, Nusa Tenggara Barat (Gambar 1). Penelitian ini dilaksanakan pada bulan April dan Juni 2002. Pengambilan contoh dan pengamatan mikrohabitat teripang dilakukan dengan menggunakan alat scuba diving pada kedalaman $2 \mathrm{~m}-15 \mathrm{~m}$ pada waktu air menjelang pasang. Pada setiap lokasi penelitian ditarik 5 garis transek ke arah laut sepanjang 100 meter dengan menggunakan transek kwadran yang berukuran $1 \mathrm{~m} \mathrm{x} 1 \mathrm{~m}$, jarak antara dua garis transek adalah 20 meter. Teripang yang terliput dalam kwadran transek dihitung jumlah individunya. Nama jenis teripang diidentifikasi menurut buku petunjuk Rowe (1969), Rowe \& Doty (1977) serta Clark \& Rowe (1971).

Analisa data yang dilakukan adalah perhitungan frekuensi kehadiran, kelimpahan dan kepadatan dengan berdasar cara yang diuraikan oleh Misra (1968).

\section{Hasil dan Pembahasan}

\section{Keadaan Umum Daerah Penelitian}

Pulau Sudak dan Pulau Nanggu mempunyai tipe habitat yang sama. Dari arah pantai menuju tubir terdiri dari zonasi pasir, tumbuhan lamun, rumput laut dan terakhir adalah terumbu karang. Perairan pantai di 2 lokasi masih dalam kondisi asri. Seluruh stasiun pengamatan merupakan perairan pantai yang jernih, landai dan bersubstrat pasir yang banyak ditumbuhi lamun dari jenis Thallasia hemprichii dan Enhalus acroides dan juga rumput laut dari jenis Gracilaria $s p$, dan Sargassum sp, kedua jenis rumput laut ini tumbuh subur terutama pada jarak $50-200 \mathrm{~m}$ dari garis pantai, yang berbatasan dengan daerah terumbu karang.

\section{Frekuensi Kehadiran, Kepadatan dan Kelimpahan}

Dari hasil identifikasi contoh sampel teripang didapatkan 11 jenis teripang yang dapat digolongkan dalam 2 suku (Tabel 1). Ke sebelas jenis teripang yang didapatkan tergolong dalam ordo Aspidochirotida. Menurut Bakus (1973) ordo Aspidochirotida merupakan karakteristik yang hidup di perairan tropis yang jernih. Hyman (1955) mengemukakan bahwa daerah Indo-Pasifik bagian barat merupakan daerah yang kaya akan jenis teripang Holothuria, Stichopus dan Actinopyga. Hasil penelitian Tamanampo $d k k$ (1989) di perairan terumbu karang Pulau Bunaken, Sulawesi Utara mendapatkan 10 jenis dan Rumahrupete et al (1990) di perairan Tanimbar, Maluku Tenggara mendapatkan 12 jenis sedang Yusron (1997) di perairan Kai Kecil, Maluku Tenggara menemukan 12 jenis teripang yang mempunyai nilai ekonomi penting.

Hasil analisis data menunjukkan terlihat bahwa frekuensi kehadiran, kepadatan dan kelimpahan mempunyai nilai bervariasi (Tabel 1 ). Frekuensi kehadiran tinggi didapatkan pada jenis Holothuria scabra $(48,86 \%)$, H. atra $(36,32 \%), \quad H$. nobilis $(34,63 \%)$ dan Bohadschia marmorata $(30,72 \%)$ pada lokasi Pulau Sudak, dan pada lokasi Pulau Nanggu didapatkan kehadiran tertinggi pada jenis Holothuria scabra $(46,24 \%), \quad H$. atra $(34,32 \%), \quad H$. nobilis $(28,84 \%)$ dan Bohadschia argus (26,18\%), sedangkan jenis lain di bawah $26 \%$. Jenis tersebut di atas memiliki sebaran yang lebih luas daripada jenis lainnya. Karena jenis-jenis tersebut selalu ditemukan di dasar perairan berpasir, komunitas lamun, rumput laut dan terumbu karang. Sedangkan hasil penelitian Rajab $d k k$ (1994) di perairan pantai Sulawesi Utara mendapatkan frekuensi kehadiran tertinggi pada jenis $H$. scabra (60\%), disusul oleh $H$. edulis dan $H$. leucospilota masing-masing 53,7 $\%, H$. atra $(33,3 \%), H$. verucosa $(26,7 \%), B$. argus $(26,7 \%), S$. horens $(26,7 \%)$ dan $H$. hilla, B. similis, serta B. marmorata masingmasing (20,0 \%), frekuensi kehadiran jenis lainnnya berada di bawah $20 \%$. 
Pada Tabel 1 tampak bahwa kelimpahan teripang yang tergolong besar pada lokasi Pulau Sudak adalah dari jenis Holothuria scabra $\left(2,38 \mathrm{ind} / \mathrm{m}^{2}\right)$ dan Bochadschia marmorata $\left(2,36 \mathrm{ind} / \mathrm{m}^{2}\right)$, pada lokasi Pulau Nanggu jenis Holothuria scabra $\left(2,42 \mathrm{ind} / \mathrm{m}^{2}\right)$, Bochadschia marmorata $\left(2,36 \mathrm{ind} / \mathrm{m}^{2}\right)$ dan Actinopyga miliaris $\left(2,24 \mathrm{ind} / \mathrm{m}^{2}\right)$, sedangkan jenis lainnya memiliki nilai kelimpahan lebih kecil dari 2 ind $/ \mathrm{m}^{2}$. Hasil penelitian Yusron (1977) di perairan Kai Kecil, Maluku Tenggara mencatat kelimpahan teripang yang tertinggi didapatkan pada jenis Bohadschia marmorata $(2,56 \mathrm{ind} / \mathrm{m} 2)$ dan B. $\operatorname{argus}\left(2,38 \mathrm{ind} / \mathrm{m}^{2}\right)$.

Kepadatan teripang yang tertinggi pada lokasi Pulau Sudak didapatkan dari jenis Holothuria scabra $\left(1,32 \mathrm{ind} / \mathrm{m}^{2}\right)$ dan $H$. atra (1,02 ind/m2), untuk lokasi Pulau Nanggu adalah jenis Holothuria scabra $\left(1,26 \mathrm{ind} / \mathrm{m}^{2}\right)$, H. atra $\left(1,24 \mathrm{ind} / \mathrm{m}^{2}\right)$ dan Bohadschia argus $\left(1,02 \mathrm{ind} / \mathrm{m}^{2}\right)$. Kepadatan yang tertinggi dari jenis-jenis tersebut di atas dimungkinkan oleh kemampuan mereka menempati berbagai habitat sehingga lebih banyak pula kesempatan berkembang. Kepadatan yang rendah selain dimungkinkan oleh kurangnya kemampuan bersaing dalam menempati habitat, juga disebabkan oleh eksploitasi yang berlebihan. Sedangkan hasil penelitian Tamanampo $d k k$ (1989) di perairan Pulau Bunaken (Sulawesi Utara) mencatat kepadatan teripang yang tinggi dari jenis Stichopus chloronotus (1,02 ind $/ \mathrm{m} 2), B$. argus $(0,97 \mathrm{ind} / \mathrm{m} 2)$ dan $H$. atra (0,78 ind/m2). Hasil penelitian Yusron (1997) di perairan Kai Kecil, Maluku Tenggara mencatat kepadatan teripang yang tinggi dari jenis $H$. atra $(1,03$ ind $/ \mathrm{m} 2), B$. marmorata (0,97 ind/m2) dan H. edulis $(0,81 \mathrm{ind} / \mathrm{m} 2)$.

Pada Tabel 2 terlihat umumnya teripang menyukai mikrohabitat karang, namun 6 jenis di antaranya menempati rumput laut , 4 jenis menempati pasir dan 2 jenis menempati mikrohabitat lamun. Gustato \& Villari dalam Heryanto (1984) mengemukakan bahwa di daerah karang dan rumput laut cukup banyak ditemukan teripang. Banyaknya teripang di mikrohabitat tersebut oleh karena kebutuhan perlindungan dari sinar matahari. Menurut Hyman (1955), teripang peka terhadap sinar matahari, sehingga teripang lebih banyak yang bersifat phototaxis negatif. Jenis-jenis $B$. marmorata dan $H$. atra yang terdapat di mikrohabitat pasir mempunyai kemampuan menghindari cahaya sinar matahari. $B$. marmorata dan $H$. scabra mampu membenamkan diri di pasir, sedangkan $H$. atra menempeli badannya dengan butiran pasir halus. Bakus (1973) mengemukakan bahwa pasir yang menempel pada tubuh $H$. atra memantulkan cahaya dan membuat suhu tubuhnya lebih rendah. Sedangkan hasil penelitian Tamanampo $d k k$ (1989) mendapatkan 10 jenis teripang yang hidup di mikrohabitat karang, 5 jenis hidup di mikrohabitat rumput laut yaitu jenis Holothuria atra, H. nobilis, H. leucospilota, Bohadschia argus dan Stichopus chloronotus dan 2 jenis di mikrohabitat pasir yaitu jenis $H$. atra dan $B$. marmorata.

\section{Daftar Pustaka}

Azis, A. 1987. Beberapa catatan tentang perikanan teripang di Indonesia dan Kawasan Indo-Pasifik Barat. Oseana, 12 (2) : $68-78$.

Bakus, G.J. 1973. The biology and ecology of tropical Holothurians. In Biology and geology of coral reefs (Jones, Q.A. \& Endean, eds) Vol II. Acad. Press, New York : 247 - 270.

Clark, A. M and F. W. E, Rowe. 1971. Monograph of shallow-water Indo West Pasific Echinoderms. Trustees of the British Museum (Natural History). London : 171 - 210.

Conand, C and N. A. Sloan. 1989. World fisheries for echinoderm. In : Marine invertebrata. Fisheries, their assesment and management. (J.F. Coddy, ed). John Wiley and Sons. Inc : $647-663$.

Conand, C and F.W. E, Rowe, 1989. World fisheries for echinoderm. In : Marine invertebrata. Fisheries, their assesment and management. (J.F. Coddy, ed). John Wiley and Sons. Inc : 647-663.

Misra, R. 1968. Ecological workbook. Oxford \& IBM. Publs. Co. New. Delhi : 224 pp. 
Eys, E. Van. 1986. The International market for sea cucumber. Infofish, marketing digest No. 5 (86): 41 - 44.

Hyman, L. H. 1955. The Invertebrata Echinodermata VII. Class Holothuroidea, the coelomate vol IV. Mac Graw-Hill Book. Company, New York : 212 - 224.

Heryanto, 1984. Suatu studi tentang kepadatan dan penyebaran berbagai jenis teripang $($ Echinodermata $=$ Holothuroidea $) \mathrm{di}$ pesisir gugus Pulau Pari Teluk Jakarta. Karya Ilmiah. Fakultas Perikanan IPB. Bogor : 70 hal.

Rowe, F.W.E. 1969. A Review of family Holothuroidae (Holothuroidae = Aspidochirotida). Bull.Br. Mus. Nat. His. Zool. London : 117 - 170.

Rumahrupete, B; A. Choliq dan J. Letelay. 1990. Kerapatan dan kelimpahan teripang (Holothuria spp.) di pantai Pulau Yamdena, Kecamatan Tanimbar Selatan. Jur. Penel. Perik. Laut. 55 : 41 -48 .
Rajab, A.W dan E. Yusron, 1994. Pengamatan teripang (Holothuroidea) di perairan pantai Sulawesi Utara, dalam Perairan Maluku dan sekitarnya. Vol $6: 41-46$.

Sloan, N. A. 1985. Echinoderms fisheries of the world: a. review. In : Keegan, B and B, O. Connor, Echinodermata, Balkema : $109-124$.

Tamanampo, F.W.S; M. Rondo dan M.S. Salaki. 1989. Potensi dan komunitas teripang (Holothuroidea) di rataan terumbu karang Pulau Bunaken, Sulawesi Utara. Jur. Fak. Per. Unsrat. 1. (1): 25 - 32.

Yusron, E. 1997. Struktur komunitas teripang (Holothuroidea) di rataan terumbu karang Kepulauan Kai Kecil, Maluku Tenggara. Prosiding Seminar Nasional Pengelolaan Terumbu Karang. Jakarta 10 - 12 Oktober 1995. : 132 - 136.

Rowe, F. W. E. and J. E. Doty. 1977. The Shallow - water Holothurian of Guam. Micronesica 13 (2) : 217 - 250. 
Tabel 1. Komposisi jenis, frekuensi kehadiran, kelimpahan dan kepadatan teripang pada 2 lokasi di perairan Sekotong - Lombok Barat, Nusa Tenggara Barat.

\begin{tabular}{|c|c|c|c|c|c|c|c|}
\hline \multirow[b]{3}{*}{ No } & \multirow{3}{*}{$\begin{array}{l}\text { Familia/Jenis } \\
\text { Holothuriidae }\end{array}$} & \multicolumn{6}{|c|}{ Lok a s i } \\
\hline & & \multicolumn{3}{|c|}{ Pulau Sudak } & \multicolumn{3}{|c|}{ Pulau Nanggu } \\
\hline & & $\begin{array}{c}\text { Frek } \\
(\%) \\
\end{array}$ & $\begin{array}{c}\text { Klph } \\
\left(\text { Ind } / \mathbf{m}^{2}\right)\end{array}$ & $\begin{array}{c}\text { Kpdt } \\
\left(\text { Ind } / \mathbf{m}^{2}\right)\end{array}$ & $\begin{array}{c}\text { Frek } \\
(\%)\end{array}$ & $\begin{array}{c}\text { Klph } \\
\left(\text { Ind } / \mathbf{m}^{2}\right)\end{array}$ & $\begin{array}{c}\text { Kpdt } \\
\left(\text { Ind } / \mathbf{m}^{2}\right)\end{array}$ \\
\hline 1. & Actinopyga lecanora & 12,42 & 1,43 & 0,16 & 12,54 & 1,42 & 0,18 \\
\hline 2. & A.miliaris & 7,28 & 1,68 & 0,14 & 5,34 & 2,24 & 0,12 \\
\hline 3. & Bochadschia argus & 24,48 & 1,12 & 0,68 & 22,18 & 1,26 & 1,02 \\
\hline 4. & B. marmorata & 30,72 & 2,36 & 0,42 & 28,14 & 2,12 & 0,38 \\
\hline 5. & Holothuria atra & 34,67 & 1,34 & 1,02 & 28,84 & 1,36 & 1,24 \\
\hline 6. & H. edulis & 36,32 & 1,12 & 0,26 & 34,16 & 1,28 & 0,36 \\
\hline 7. & H. nobilis & 18,16 & 1,24 & 0,23 & 16,34 & 1,14 & 0,24 \\
\hline 8. & H. leucospilota & 12,34 & 1,38 & 0,18 & 14,62 & 1,42 & 0,16 \\
\hline 9. & H. scabra & 48,86 & 2,38 & 1,32 & 46,24 & 2,42 & 1,26 \\
\hline \multicolumn{8}{|c|}{ Stichopodidae } \\
\hline 10. & S. variegatus & 6,48 & 1,32 & 0,18 & 7,14 & 1,26 & 0,14 \\
\hline 11. & Thelenota ananas & 5,46 & 1,16 & 0,12 & 4,48 & 1,14 & 0,10 \\
\hline
\end{tabular}

Keterangan :

Frek $=$ Frekuensi,$\quad$ Klph $=$ Kelimpahan,$\quad$ Kpdt $=$ Kepadatan

Tabel 2. Penyebaran teripang berdasarkan mikrohabitat di perairan Sekotong, Lombok Barat, Nusa Tenggara Barat

\begin{tabular}{clcccc}
\hline No & \multicolumn{1}{c}{ Jenis } & Pasir & Rumput laut & Lamun & Karang \\
\hline \hline 1. & Actinopyga lecanora & - & - & - & + \\
2. & A.miliaris & - & - & - & + \\
3. & Bochadschia argus & + & + & - & + \\
4. & B. marmorata & + & + & - & + \\
5. & Holothuria atra & + & - & - & + \\
6. & H. edulis & - & - & + & + \\
7. & H. nobilis & - & + & - & + \\
8. & H. leucospilota & + & + & + & + \\
9. & H. sacbra & - & + & - & + \\
10. & S. variegatus & - & - & - & + \\
11. & Thelenota ananas & & & & + \\
\hline
\end{tabular}

Keterangan : (-) : tidak terdapat pada mikrohabitat

$(+)$ : terdapat pada mikrohabitat 
Sumberdaya Teripang (Holothuroidea) Di Kepulauan Sekotong - Lombok Barat, Nusa Tenggara Barat 